\title{
High rates of obesity prevalence in adults living in Central Greece: Data from the ARGOS Study
}

\author{
George N. Koukoulis ${ }^{1}$, Christina Sakka ${ }^{1}$, Fotis Katsaros ${ }^{1}$, Maria Goutou ${ }^{1}$, Sofia Tsirona ${ }^{1}$, \\ Efthimia Tsiapali ${ }^{1}$, Aristea Piterou ${ }^{1}$, Ioannis Stefanidis ${ }^{2}$, Nikolaos Stathakis ${ }^{3}$
}

${ }^{1}$ Department of Endocrinology and Metabolism, ${ }^{2}$ Department of Nephrology and ${ }^{3}$ Department of Internal Medicine, University Hospital, School of Medicine, University of Thessaly, Larissa, Greece

\begin{abstract}
OBJECTIVE: To investigate the prevalence of obesity in adults of a large region of Central Greece. DESIGN: The target group was adults aged 18 to 79 years who were residents of the region of Thessaly for at least one year. A sample of 852 individuals stratified for sex and age were included. Each subject underwent a thorough physical examination and body mass index (BMI) was calculated from body weight and height. Waist and hip circumferences as well as body fat content were additionally measured. RESULTS: Mean (SD) BMI for the total population was $27.5 \pm 5.5$ and was significantly higher in males than in females $(28.2 \pm 4.4 \mathrm{vs} .26 .9 \pm 6.2$, p<0.001). The overall prevalence of obesity was $26.6 \%$ distributed equally between men $(27.8 \%)$ and women $(25.6 \%)$, whereas prevalence of overweight was $39.4 \%$ with male predominance (50.8\% vs. $29.3 \%$, p<0.001). Morbid obesity (MO) was found in $3.5 \%$ with female predominance. The prevalence of central obesity, using waist circumference cut-off points $(>102 \mathrm{~cm}$ for men, $>88 \mathrm{~cm}$ for women), was comparable in males $(\mathbf{4 0 . 4 \%})$ and females $(35.3 \%)$. There was a positive association between obesity, central obesity, and age. The prevalence of overweight (19.5\%) and obesity (9.4\%) in the age-range of 18-29 years almost doubled in the next decade of age and attained the highest value, respectively, in the age-range of 50 to $59(48.2 \%)$, and of 60 to 70 years group (38.9\%). CONCLUSIONS: The rates of overweight and obesity in the population of Thessaly are relatively high with overweight being more prominent in males than in females, whereas MO was higher in females compared to males.
\end{abstract}

Key words: Central obesity, Morbid obesity, Obesity, Overweight

Address for correspondence:

George N. Koukoulis, Associate Professor in Endocrinology,

Department of Endocrinology and Metabolic Diseases,

Larissa University Hospital, Biopolis, 41 110, Larissa, Greece,

Tel.: (+30) 2413502820, Fax: (+30) 2413501567,

e-mail: gnkouk@med.uth.gr

Received 10-01-10, Revised 20-04-10, Accepted 10-05-10

\section{INTRODUCTION}

Obesity (OB), a health problem associated with serious clinical consequences, is attaining epidemic proportions in both developed and developing societies. ${ }^{1}$ In the last four decades the age-adjusted prevalence of $\mathrm{OB}$ has dramatically increased in several 
western countries. ${ }^{2-5}$ The current prevalence of $\mathrm{OB}$ is $10-25 \%$ in most western European countries ${ }^{3}$ and $30 \%$ in the USA. ${ }^{5}$ In addition, data from the WHO Global Database ${ }^{6}$ on Body Mass Index (BMI) indicate that rates of $\mathrm{OB}$ in Europe and North America are even higher. The recent report of the WHO on Diet, Nutrition, and the Prevention of Chronic Diseases placed $\mathrm{OB}$ at the top of the public health agenda as the foremost avoidable risk factor for a wide range of non-communicable diseases.?

Obesity in adults is associated with excess risk of coronary heart disease (CHD) and mortality. ${ }^{8} \mathrm{CHD}$ mortality rates have been found to be much lower in Mediterranean countries than in northern European countries. This was first reported in 1960 when the Seven Countries' Study was conducted ${ }^{9}$ and remained valid in the reevaluation of $1991 .{ }^{10}$ However, in 1991, compared to 1960, a significant increase in the BMI of Greek participants was observed. ${ }^{11}$

Data on the prevalence of obesity in Greece are limited. During the last decade a limited number of cross-sectional studies examining the prevalence of OB in Greek adults have been conducted. In a recent nationwide, cross-sectional epidemiological survey $^{12}$ the reported prevalence of obesity in adults was $22.5 \%$, an incidence significantly higher than that found in two local studies conducted in different regions of the country, namely Attica ${ }^{13}$ and northern Greece. ${ }^{14}$ However, there were limitations in the above-mentioned studies. The study conducted in Attica ${ }^{13}$ included mainly subjects living in an urban area where OB is less prevalent, ${ }^{15}$ while in the other local study ${ }^{13}$ the estimation of OB prevalence was based on self-reported data, a method underestimating BMI. ${ }^{16}$ This was also the case in the nationwide epidemiological survey, ${ }^{12}$ but more importantly, the studied sample was not age-stratified to the Greek adult population. Therefore, we decided to conduct a well-designed epidemiological survey in Thessaly, a large region of the country with urban and rural areas, in order to estimate the prevalence of $\mathrm{OB}$ and compare it to recently published data.

\section{SUBJECTS AND METHODS}

\section{Sample Selection}

The Adult Regional Greek Obesity Survey (ARGOS) is a community-based health and nutrition study, which is being carried out in the region of Thessaly, Central Greece, with a population of 625,000 adult inhabitants living in urban (60\%) and rural (40\%) areas. ${ }^{17}$ According to the population census, areas with less than 2,000 inhabitants were defined as rural. A cluster random sample was drawn from the adult population. The target group was adults, aged 18 to 79 years, who were residents of the region of Thessaly for at least one year. The sample size for our population survey was estimated according to power analysis accepting a confidence level of $95 \%$ and a margin of error of approximately $3 \%$ while taking into account the census of 2001 and the previous Greek studies which had estimated the prevalence of obesity in adults. The data were collected from 2001 through 2003. The goal of the survey was to gain insights into the prevalence of obesity, its metabolic consequences and the adults' nutrition habits.

For random sample selection the cluster (or area) sampling technique was used..$^{18}$ The total population was divided into geographical clusters corresponding to the four provinces of the whole region. The sample size in each province was estimated according to its population. The sample was then collected from the capital of each province (typically the main city of the province) as well as from other towns and villages, which were selected using simple random sampling. ${ }^{18}$ The sample size was proportional to the population of the capital, towns, and villages of each one of the four provinces according to the census of 2001 of the National Service for Statistics. In the four main cities the sample was selected by using city blocks as clusters and complete households within the cluster were surveyed. In the towns and villages, the number of local households was divided by the estimated sample size in each one and the result was used as the factor for household selection. Sampling was restricted to adults only and from each household one adult was selected randomly.

An interview was arranged for each participant who was instructed to report in the morning at 09.00 after an overnight fast (at least 12 hours). Subjects were asked to bring all of their regular medications with them. The overall response rate was $79 \%$. From 1,152 inhabitants who were contacted, 958 agreed to participate; however, the study was completed in 915 adults of both sexes with age ranging from 18-79 years. 
Informed consent was obtained from all responders and the protocol was reviewed and approved by the Ethics Committee of the University Hospital of Larissa (University of Thessaly, School of Medicine).

\section{Procedure}

The participants were interviewed in a public health office. Each subject underwent a thorough physical examination. Blood pressure was measured twice on the right arm with subjects seated, after at least 20 min of rest, using a standard mercury sphygmomanometer. The mean of the two readings was registered as each individual's blood pressure. Body weight and height were measured without shoes. Weight was measured with the same level balance to the nearest 100 grams (Wunder SAN150A, maximal capacity 150 $\mathrm{Kg}$, graduations $0.1 \mathrm{Kg}$ ) and height was measured against a wall tape to the nearest $0.5 \mathrm{~cm}$. Waist and hip circumferences were measured using a plastic non-stretchable tailor's measuring tape, at a level midway between the lower rib margin and iliac crest and around the buttocks at the level of the maximum extension, respectively, to the nearest centimetre. Waist-to-hip $(\mathrm{W} / \mathrm{H})$ ratio was then calculated. The waist circumference (WC) and the $\mathrm{W} / \mathrm{H}$ ratio were used to define central obesity. A $\mathrm{W} / \mathrm{H}$ ratio $\geq 0.95$ in males and $\geq 0.80$ in females as well as a WC of $\geq 94 \mathrm{~cm}$ in males and $\geq 80 \mathrm{~cm}$ in females were considered to represent central obesity. ${ }^{19}$ The $\mathrm{WC}<94 \mathrm{~cm}$ in males and $<80 \mathrm{~cm}$ in females were considered equivalent to a BMI of 25 as it is recommended for Europeans. ${ }^{20}$ However, since a $\mathrm{WC} \geq 102$ in males and $\geq 88 \mathrm{~cm}$ in females are used to define central obesity in metabolic syndrome, we used both cut-offs. Body mass index $\left(\mathrm{BMI} ; \mathrm{kg} / \mathrm{m}^{2}\right.$ ) was calculated from the body weight (W) and height $(\mathrm{H})$ according to Quetelet's formula: $\mathrm{BMI}=\mathrm{W} / \mathrm{H}$ (the weight in kilograms divided by the square of the height in meters). ${ }^{21}$ The body fat content (\% fat mass) was assessed by means of bioelectrical impedance analysis, using a commercial bio-impedance analyser (Omron HBF 302 Body Fat Analyser, Omron Healthcare Inc., Vernon Hills, IL, USA) with the patient in standing position. Weight status was classified according to the WHO definitions: ${ }^{22}$ Underweight (UW): $\mathrm{BMI}<18.5$, normal weight (NW): BMI between 18.5 and 24.9, overweight (OW): BMI between 25 and 29.9, obese: BMI $>30$, and extremely or morbidly obese (MO): $\mathrm{BMI} \geq 40$. Each participant also completed a questionnaire inquiring about health status and health behaviours (smoking, alcohol intake, nutrition habits, etc) under medical supervision.

\section{Statistical analysis}

Normal distribution of the variables was checked by the Kolmogorov-Smirnov test. Continuous variables are presented as mean values and one standard deviation (mean (SD)) or median and interquartile range (median (IQR)) as appropriate, while qualitative variables are presented as absolute and relative frequencies. Categorical variables were tested by the use of contingency tables and the calculation of the chi-squared test, and inter-group differences were expressed as odds ratio (OR) and 95\% confidence intervals (OR, 95\% CI). Comparisons between normally distributed continuous variables were performed by the calculation of Student's t-test. In the case of asymmetric continuous variables, the tested hypotheses were based on the calculations of the nonparametric test suggested by Kruskal and Wallis. A linear regression model was developed to assess the effect of age and gender on BMI, WC, and \% body fat content. BMI and, respectively, WC and \% body fat content were defined as the dependent variable, the different age groups as the independent variable and the gender as an interaction term. All reported $P$-values are based on two-sided tests and compared to a significance level of 5\%. SPSS 10.1 software (SPSS Inc. 2002, USA) was used for all the statistical calculations.

\section{RESULTS}

Figure 1 shows the age-stratification of our sample of 915 subjects compared to that of the Thessaly region and the country's population. However, the percentage of the group in the age-range of 70 to 79 years was significantly lower compared to the country's population of the same age-range and consequently was omitted from the final analysis. Hence, 852 subjects (402 males and 450 females) were included in the analysis with an age ranging from 18 to 70 years. The gender distribution of the sample was comparable to that of the source population (males/females: our sample 47.2/52.8\%, population: $49.6 / 50.4 \%, \mathrm{p}>0.05)$. 


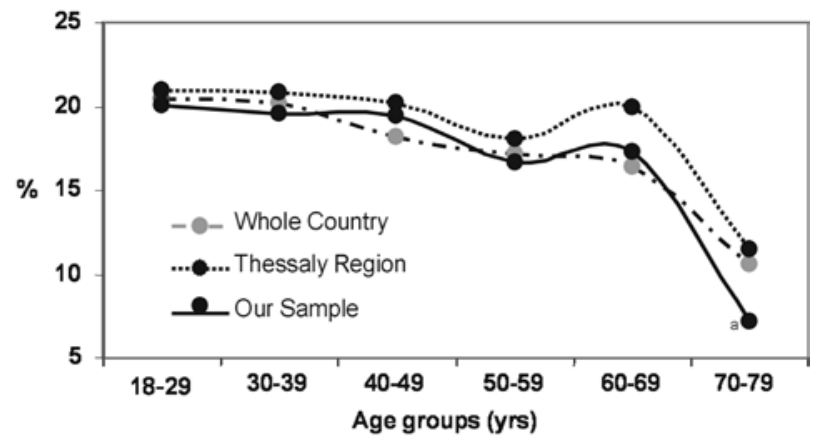

Figure 1. The age-dependent frequency distribution of the whole country population, the population of the Thessaly region, and our sample stratification.

The BMI value (mean (SD)) of the total population studied was 27.5 \pm 5.5 (range 17.5-58.3) and was significantly higher in males than in females $(28.2 \pm 4.4$ vs. $26.9 \pm 6.2, \mathrm{p}<0.001)$. In addition, $\mathrm{OB}$ was more prevalent in rural compared to urban areas (Table 1) $(33.1 \%$ vs. $17.8 \%, \mathrm{p}=0.001)$ in both males $(33.9 \%$ vs. $19.8 \%, \mathrm{p}=0.002)$ and females $(32.4 \%$ vs. $16.0 \%$, $\mathrm{p}=0.001)$. However, OW was more prevalent in rural areas only in females $(34.4 \%$ vs. $22.3 \%, \mathrm{p}=0.006)$. The inhabitants in rural areas had a significantly higher risk for increased body weight (RR 1.55, 95\% CI 1.07-2.26, $\mathrm{p}=0.026$ for males, and RR $1.84,95 \%$ CI 1.50-2.26, $\mathrm{p}<0.001$ for females).

The prevalence of UW, NW, OW, and OB in males, females, and in the total group is shown in Table 2. The overall prevalence of OB was $26.6 \%$ equally distributed among males and females $(27.9 \%$ vs. $25.6 \%, \mathrm{p}=0.601)$. The overall prevalence of OW was $39.4 \%$ but significantly more males were OW compared to females $(50.8 \%$ vs. $29.3 \%, \mathrm{p}<0.001)$. Inversely, significantly fewer males had normal weight compared to females $(20.8 \%$ vs. $43.3 \%, \mathrm{p}<0.001)$. Morbid obesity was found in $3.5 \%$ of the subjects with more females than males being in this category
Table 2. The \% distribution of the weight status, based on BMI, in males, females, and in the whole group

\begin{tabular}{lcccc}
\hline & $\begin{array}{c}\text { Under- } \\
\text { weight }\end{array}$ & $\begin{array}{c}\text { Normal } \\
\text { weight }\end{array}$ & $\begin{array}{c}\text { Over- } \\
\text { weight }\end{array}$ & Obese \\
\hline Men & 0.5 & 20.8 & 50.8 & 27.9 \\
Women & $1.8^{\mathrm{b}}$ & $43.3^{\mathrm{a}}$ & $29.3^{\mathrm{a}}$ & 25.6 \\
Whole group & 1.2 & 32.8 & 39.4 & 26.6 \\
\hline${ }^{\mathrm{a}} \mathrm{p}<0.001,{ }^{\mathrm{b}} \mathrm{p}<0.05$ for category comparison between males and \\
females
\end{tabular}

(4.7\% vs. $2.0 \%, \mathrm{p}<0.05)$. The distribution of $\mathrm{MO}$ in the various age groups in males and females is shown in Figure 2. MO was significantly higher in females compared to males only in the age group of 60-70 years $(\mathrm{p}<0.05)$.

The BMI distribution across the age groups is shown in Table 3. In the whole group as well as in males and females, BMI was found to increase with age. Linear regression analysis showed that age categories and gender were independent predictors of BMI $(p<0.001$ and $p=0.042$, respectively). Similarly, independent predictors of BMI were age categories when analysis for each gender was done separately for males $(\mathrm{p}<0.001)$ and females $(\mathrm{p}<0.001)$.

The weight status based on BMI in the whole

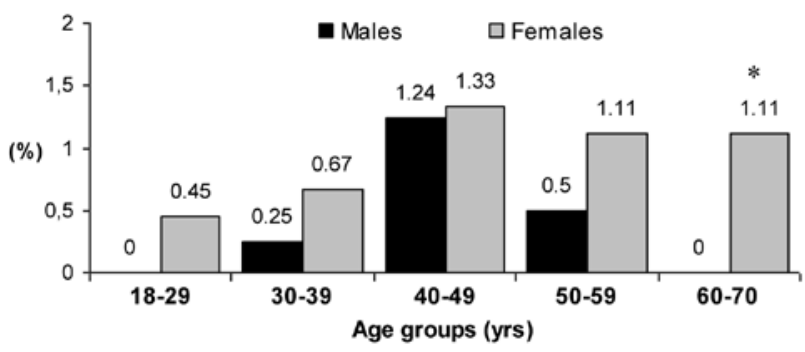

Figure 2. The frequency distribution of morbid obesity in males and females in the various age groups. ${ }^{*} \mathrm{p}<0.05$ compared to males.

Table 1. Percent of overweight and obesity in rural and urban areas in males, females, and the whole group

\begin{tabular}{|c|c|c|c|c|c|c|c|c|c|}
\hline & \multicolumn{3}{|c|}{ Whole group } & \multicolumn{3}{|c|}{ Males } & \multicolumn{3}{|c|}{ Females } \\
\hline & \multicolumn{2}{|c|}{ Area } & \multirow[b]{2}{*}{$P$ value } & \multicolumn{2}{|c|}{ Area } & \multirow[b]{2}{*}{$P$ value } & \multicolumn{2}{|c|}{ Area } & \multirow[b]{2}{*}{$P$ value } \\
\hline & Rural & Urban & & Rural & Urban & & Rural & Urban & \\
\hline Overweight (\%) & 40.7 & 37.8 & 0.435 & 47.8 & 54.6 & 0.191 & 34.4 & 22.3 & 0.006 \\
\hline Obesity (\%) & 33.1 & 17.8 & 0.001 & 33.9 & 19.8 & 0.002 & 32.4 & 16.0 & 0.001 \\
\hline
\end{tabular}


Table 3. BMI $\left(\mathrm{kg} / \mathrm{m}^{2}\right)$ distribution in males, females, and in the total study population by age groups.

\begin{tabular}{|c|c|c|c|c|c|c|}
\hline \multirow{2}{*}{$\begin{array}{l}\text { Age-groups } \\
\text { (yrs) }\end{array}$} & \multicolumn{2}{|c|}{ Total } & \multicolumn{2}{|c|}{ Males } & \multicolumn{2}{|c|}{ Females } \\
\hline & $\mathbf{N}$ & BMI & $\mathbf{N}$ & BMI & $\mathbf{N}$ & BMI \\
\hline $18-29$ & 184 & $23.8(5.4)^{*}$ & 88 & $24.3(3.5)^{*}$ & 96 & $21.9(4.8)^{*}$ \\
\hline $30-39$ & 179 & $26.3(5.6)^{*}$ & 83 & $27.9(3.5)$ & 96 & $23.9(5.5)^{*}$ \\
\hline $40-49$ & 178 & $28.8(6.8)^{*}$ & 86 & $28.7(5.9)^{*}$ & 92 & $26.4(7.3)^{*}$ \\
\hline $50-59$ & 153 & $29.1(5.3)^{*}$ & 72 & $28.2(4.5)^{*}$ & 81 & $27.5(6.5)^{*}$ \\
\hline $60-70$ & 158 & $29.4(6.7)^{*}$ & 73 & $27.5(6.0)^{*}$ & 85 & $29.3(6.2)^{*}$ \\
\hline
\end{tabular}

Values are expressed as mean (SD) with the exception of those with skewed distribution (marked with *), which are expressed as median (IQR).

In linear regression analysis, age categories and gender were independent predictors of BMI $(\mathrm{p}<0.001$ and $\mathrm{p}=0.042$, respectively). Similarly, independent predictors of BMI were age categories when analysis for each gender was done separately for males $(\mathrm{p}<0.001)$ and females $(\mathrm{p}<0.001)$.

group and in the various ages is shown in Figure 3. The prevalence of obesity in the age group 18 to 29 years was low $(9.4 \%)$ but doubled in the age group of 30 to 39 years (17.2\%) and reached a level of $33.3 \%$ and $33.1 \%$ in the age groups of 40 to 49 and 50 to 59 years, respectively. The highest prevalence of obesity was found in the age group 60 to 70 years $(38.9 \%)$. A different trend was observed in the prevalence of overweight with increasing age. It was doubled in the age group of 30 to 39 years compared to the age group 18 to 29 years $(40.8 \%$ and $19.5 \%$, respectively; $\mathrm{p}<0.001)$ and remained at comparable levels thereafter. The prevalence of normal weight was significantly lower in all age groups compared to individuals aged 18-29 years $(p<0.001)$. The lowest prevalence of normal weight was observed in the age group of 60 to 70 years $(16.2 \%)$. The prevalence of UW in the whole group (Table 2) was $1.2 \%, 1.8 \%$ in females, and $0.5 \%$ in males, $\mathrm{p}<0.05$.

The prevalence of OW and OB in males and females in the various age groups is shown in Figures 4A and 4B, respectively. Significantly more males compared to females were OW over the whole agerange $(50.8 \%$ vs. $29.3 \%$, respectively, $\mathrm{p}<0.001)$ as well as in the age groups of 18-29, 30-39, and 40-49 years, whereas in the age groups of 50-59 and 60-70 years the prevalence of OW was comparable between males and females (Figure 4A). By contrast, comparable prevalence of $\mathrm{OB}$ was found in males and females in the whole age-range as well as in the various agegroups (Figure 4B).

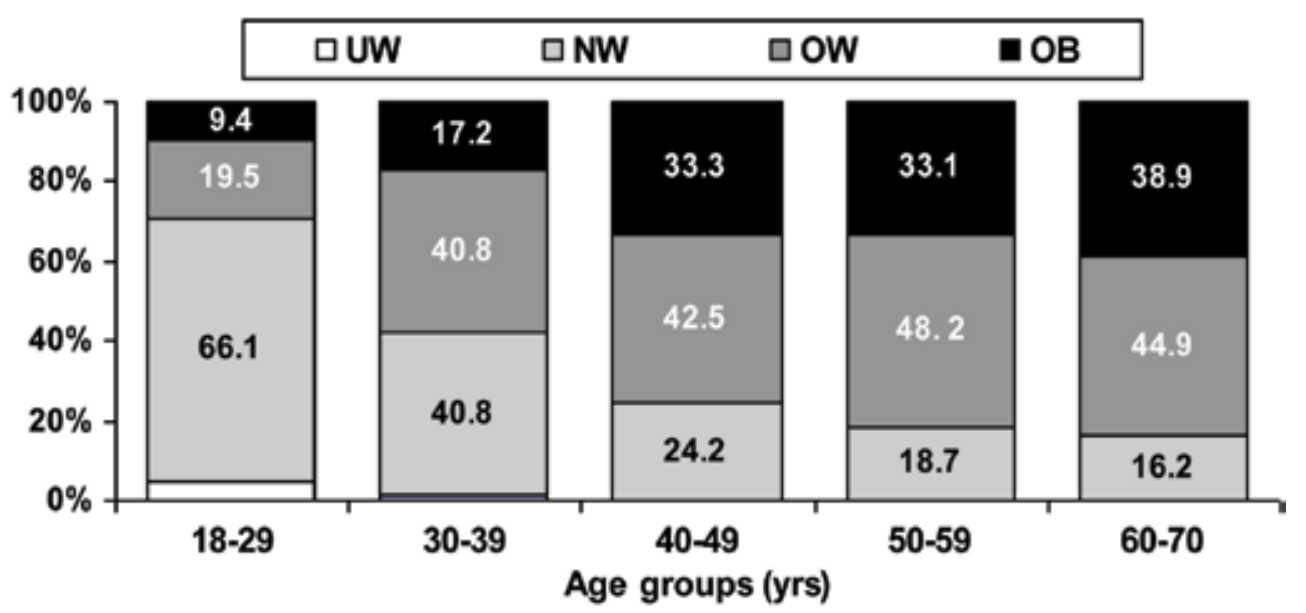

Figure 3. The weight status based on BMI in the various age groups. For statistical differences see text. (UW: under weight, NW: normal weight, OW: overweight, OB: obesity). 

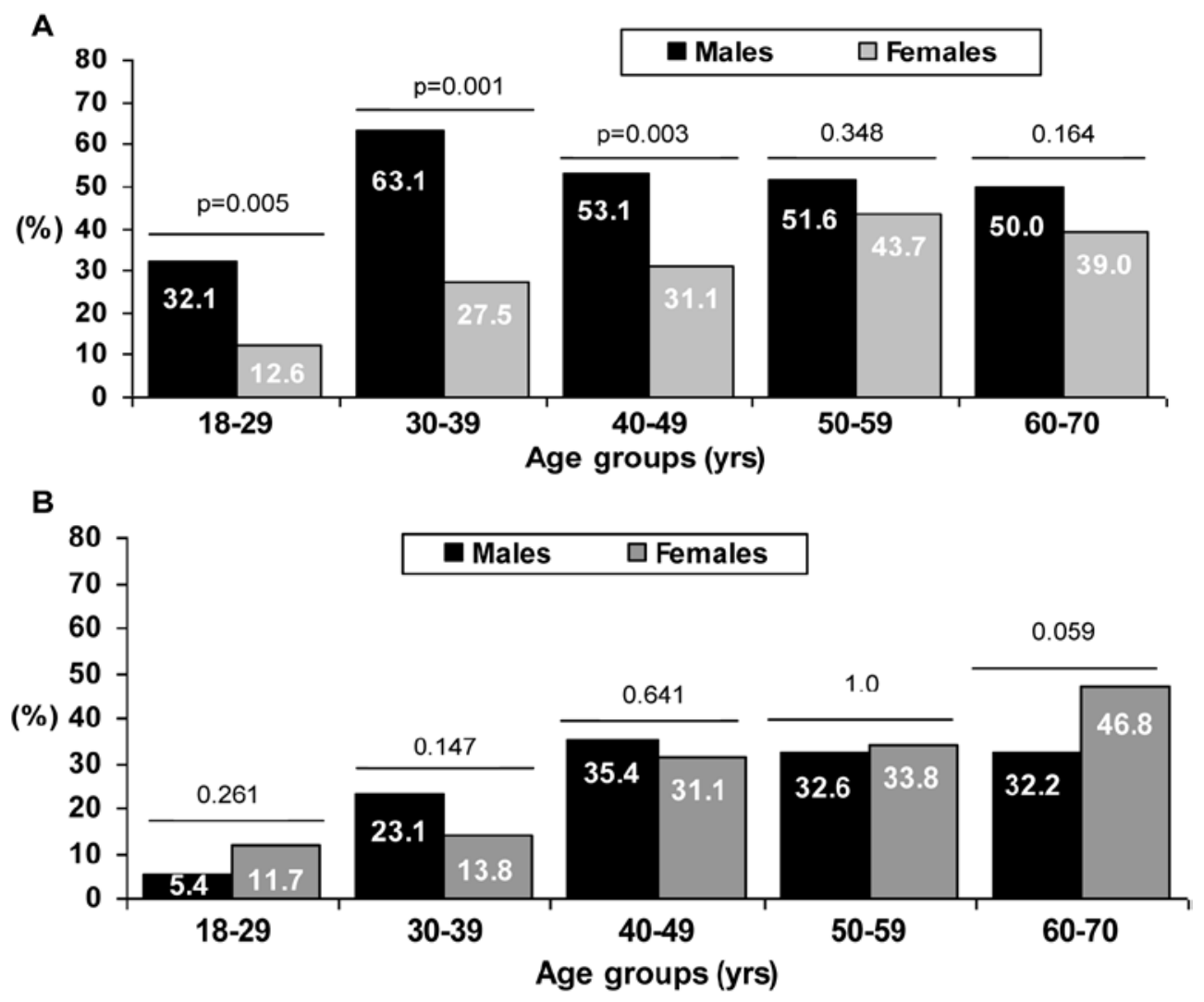

Figure 4. Distribution of overweight (A) and obese (B) subjects in the various age groups separately for males and females.

Table 4 shows the distribution of the \% fat content, $\mathrm{WC}$, and $\mathrm{W} / \mathrm{H}$ ratio across the age categories in males and females. For the total population WC was $93.01 \pm 15.16 \mathrm{~cm}(99.0 \pm 15.0 \mathrm{~cm}$ in males, $84.0 \pm 21.0$ in females). The $\mathrm{W} / \mathrm{H}$ ratio in the entire group was $0.88 \pm 0.09 \mathrm{~cm}(0.95 \pm 0.09 \mathrm{~cm}$ in males, $0.81 \pm 0.12 \mathrm{~cm}$ in females). Linear regression analysis showed that age category $(\mathrm{p}<0.001)$, BMI $(\mathrm{p}<0.001)$, and gender

Table 4. Percent body fat content, WC, and $\mathrm{W} / \mathrm{H}$ ratio in males and females by age categories

\begin{tabular}{|c|c|c|c|c|c|c|c|c|}
\hline \multirow[b]{2}{*}{$\begin{array}{l}\text { Age category } \\
\text { (yrs) }\end{array}$} & \multicolumn{4}{|c|}{ Males } & \multicolumn{4}{|c|}{ Females } \\
\hline & $\mathbf{N}$ & $\begin{array}{c}\text { Body fat } \\
\text { content }(\%)\end{array}$ & $\mathrm{WC}(\mathrm{cm})$ & $\mathrm{W} / \mathrm{H}$ ratio & $\mathbf{N}$ & $\begin{array}{c}\text { Body fat } \\
\text { content }(\%)\end{array}$ & $\mathrm{WC}(\mathrm{cm})$ & $\mathrm{W} / \mathrm{H}$ ratio \\
\hline $18-29$ & 88 & $16.3(4.5)$ & $89.5(12.4)^{*}$ & $0.88(0.09)^{*}$ & 96 & $24.2(7.6)$ & $74.0 \quad(14.0)^{*}$ & $0.77(0.09)^{*}$ \\
\hline $30-39$ & 83 & $21.0 \quad(5.9)$ & $96.9 \quad(9.8)$ & $0.91 \quad(0.05)$ & 96 & $27.8(7.4)$ & $79.0(15.5)^{*}$ & $0.79(0.08)^{*}$ \\
\hline $40-49$ & 86 & $25.3(5.8)$ & $100.0(14.8)^{*}$ & $0.94(0.08)^{*}$ & 92 & $32.7 \quad(7.1)$ & $84.5(19.5)^{*}$ & $0.83 \quad(0.07)$ \\
\hline $50-59$ & 72 & $26.2(5.0)$ & 101.7 (12.7) & $0.97(0.09)^{*}$ & 81 & $37.1(7.6)^{*}$ & $91.0 \quad(17.0)^{*}$ & $0.85 \quad(0.09)$ \\
\hline $60-70$ & 73 & $28.7(6.4)^{*}$ & $102.0(15.0)^{*}$ & $0.98(0.09)^{*}$ & 85 & $38.6 \quad(5.9)$ & 99.8 (11.8) & $0.90 \quad(0.08)$ \\
\hline $18-70$ & 402 & $24.6(9.2)^{*}$ & $99.0(15.0)^{*}$ & $0.95(0.09)^{*}$ & 450 & $30.9(8.9)$ & $84.0(21.0)^{*}$ & $0.81(0.12)^{*}$ \\
\hline
\end{tabular}

WC: Waist circumference, W/H: Waist to Hip ratio

Values are expressed as mean (SD) with the exception of those with skewed distribution (marked with *), which are expressed as median (IQR).

In linear regression analysis, age category $(\mathrm{p}<0.001)$, and gender $(\mathrm{p}<0.001)$ were independent predictors of $\%$ body fat content, WC, and $\mathrm{W} / \mathrm{H}$ ratio. When analysis for each gender was done separately, age category $(\mathrm{p}<0.001)$ was independent predictor of $\%$ body fat content, $\mathrm{WC}$, and $\mathrm{W} / \mathrm{H}$ ratio. 
$(\mathrm{p}<0.001)$ were independent predictors of $\%$ body fat content, $\mathrm{WC}$, and $\mathrm{W} / \mathrm{H}$ ratio. When analysis for each gender was done separately, independent predictors of $\%$ body fat content, $\mathrm{WC}$, and $\mathrm{W} / \mathrm{H}$ ratio were age category $(\mathrm{p}<0.001)$ and BMI $(\mathrm{p}<0.001)$.

Mean waist and hip circumference and $\%$ of subjects with abnormal $\mathrm{WC}$ and $\mathrm{W} / \mathrm{H}$ ratio according to BMI values are shown in Table 5. The increase of BMI was associated with enhanced frequency of abdominal obesity in both sexes independently of the criterion used for defining central obesity. The prevalence of central obesity (WC $\geq 102 \mathrm{~cm}$ for men and $\geq 88 \mathrm{~cm}$ for women) was comparable between men and women $(40.4 \%$ vs. $35.3 \%, p=0.137)$. Abdominal obesity was present in more than $90 \%$ of obese subjects of both sexes and in a significantly higher percentage of overweight females compared to males $(46.2 \%$ vs. $18.1 \% \mathrm{p}<0.001) .2 .3 \%$ of males and $5.9 \%$ of females with normal body weight had central obesity. The prevalence of central obesity was higher when the criteria recommended for Europeans were used.

\section{DISCUSSION}

This is the first survey that has been conducted in a relatively large sample of the adult population of Thessaly stratified for age and sex to regional and whole-country population, providing data on the prevalence of excess body weight. Thessaly is a large region of central Greece with urban and rural areas. An impressively high number of adults were found to be either obese $(26.6 \%)$ or overweight $(39.4 \%)$ with OB being equally distributed between sexes, whereas significantly more males were OW compared to females (50.8\% vs. $29.3 \%)$.

According to published studies, OB in Greek adults ranges from $17.8 \%$ to $26.6 \%$. The overall prevalence of $\mathrm{OB}$ found in Thessaly was higher compared to respective prevalence found by Krassas et $\mathrm{al}^{14}$ in a sample based on the Central Macedonia population (19.9\%), and Panagiotakos et $\mathrm{al}^{13}$ in a sample from the geographic area of Athens, the Attica area (17.8\%). Although real differences in the prevalence of $\mathrm{OB}$ in different regions of the country cannot be excluded, it appears that the methodology used (reported and not measured height and weight), the population sampled, and the lack of age stratification in the above-mentioned local surveys might explain, at least in part, the discrepancy in the results obtained. The telephone self-reported information on height and weight by participants and the sampled population from an urban area might have underestimated ${ }^{19,20}$ the prevalence of obesity in Central Macedonia in the study of Krassas et al, ${ }^{14}$ since weight underestimation is most likely to be greater among females than

Table 5. Waist and hip circumference and percent of subjects with abnormal WC and $\mathrm{W} / \mathrm{H}$ ratio according to BMI values in males and females.

\begin{tabular}{|c|c|c|c|c|c|c|}
\hline \multirow[b]{2}{*}{ BMI values $\left(\mathrm{kg} / \mathrm{m}^{2}\right)$} & \multicolumn{3}{|c|}{ Males } & \multicolumn{3}{|c|}{ Females } \\
\hline & $<25$ & $25-29.9$ & $>\mathbf{3 0}$ & $<25$ & $25-29.9$ & $>\mathbf{3 0}$ \\
\hline No. of participants & 86 & 204 & 112 & 203 & 132 & 115 \\
\hline $\mathrm{WC}(\mathrm{cm})$ & $88.0(10.0)^{*}$ & $98.0(7.0)^{*}$ & $112.0(12.5)^{*}$ & $75.0(8.5)^{*}$ & $88.0(11.0)^{*}$ & $103.0(17.0)^{*}$ \\
\hline Abnormal WC $(\%)^{\mathrm{a}}$ & 16.3 & 77.5 & 100 & 23.2 & 91.7 & 100 \\
\hline Abnormal WC $(\%)^{\mathrm{b}}$ & 2.3 & 18.1 & 92.0 & 5.9 & 46.2 & 94.8 \\
\hline Hip circumference $(\mathrm{cm})$ & $98.0(8.0)^{*}$ & $105.0(8.0)^{*}$ & $114.0(8.8)^{*}$ & $97.0(9.0)^{*}$ & $106.5(5.4)$ & $116.0(12.0)^{*}$ \\
\hline $\mathrm{W} / \mathrm{H}$ ratio & $0.90(0.11)^{*}$ & $0.94(0.08)^{*}$ & $0.98(0.10)^{*}$ & $0.78(0.09)^{*}$ & $0.82(0.10)^{*}$ & $0.88(0.08)^{*}$ \\
\hline Abnormal $\mathrm{W} / \mathrm{H}$ ratio $(\%)^{\mathrm{a}}$ & 19.8 & 47.5 & 71.4 & 38.4 & 63.6 & 89.6 \\
\hline Abnormal $\mathrm{W} / \mathrm{H}$ ratio $(\%)^{\mathrm{b}}$ & 4.7 & 14.7 & 39.3 & 10.8 & 37.9 & 64.3 \\
\hline
\end{tabular}

WC: Waist circumference, W/H: Waist to Hip ratio, BMI: Body Mass Index

Values are expressed as mean (SD) with the exception of those with skewed distribution (marked with*), which are expressed as median (IQR).

${ }^{a}$ for males and females, respectively, waist circumference $\geq 94 \mathrm{~cm}$ and $\geq 80 \mathrm{~cm}$ and waist $/$ hip ratio $\geq 0.95$ and $\geq 0.80$.

${ }^{\mathrm{b}}$ for males and females, respectively, waist circumference $>102 \mathrm{~cm}$ and $>88 \mathrm{~cm}$ and waist/hip ratio $>1$ and $>0.85$. 
among males in anthropometric values obtained by telephone. ${ }^{23}$ In addition, people with no telephone might be of lower socioeconomic status, a factor associated with OB. ${ }^{24}$ Similarly, the urbanization of the Attica area, represented mostly by the city of Athens, may explain the lower overall prevalence of $\mathrm{OB}$ in the survey conducted in person by Panagiotakos et al. ${ }^{13}$ However, in a study conducted in person in 9,649 participants aged 50 to 64 years, from all over the country, ${ }^{25}$ percent of subjects with BMI $>25$ was comparable to our results in the same age group ( $80.5 \%$ vs. $81.0 \%$ for males, $82.1 \%$ vs. $81.7 \%$ for females, respectively).

Compared to the results of the nationwide study by Kapantais et al, ${ }^{12}$ the overall prevalence of OB in the females of our study was significantly higher, whereas in males its prevalence was comparable. The lower prevalence of $\mathrm{OB}$ in this study ${ }^{12}$ might be attributed to the procedure followed, namely self-reported height and weight as well as the lack of age stratification. Compared to the population of the entire country, in the study of Kapantais et $\mathrm{al}^{12}$ the proportion of males in the age-range of 60 to 69 years was 3.4\% (14.6\% in the general population) and of females in the age-ranges of 50 to 59 and of 60 to 69 years it was $4.8 \%$ and $3.1 \%$, respectively $(15.3 \%$ and $16.1 \%$ in the general population). In this particular study, the highest prevalence of $\mathrm{OB}$ in females was observed in an age-range similar to ours (60 to 69 years), although a smaller proportion of females older than 60 years was included. Older adults were more likely to be obese than younger subjects. This was also the case in our study where BMI as well as percent body fat content were found to increase with age.

Moreover, the prevalence of MO in our population was found to be close to that found in non-Hispanic white Americans..$^{27}$ This finding is particularly alarming when one considers that higher body weight in adults is associated with increased incidence of diabetes mellitus, hyperlipidemia, hypertension, nonalcoholic steatohepatitis, obstructive sleep apnea, certain forms of cancer, musculoskeletal disorders, and CHD which are responsible for higher disability, morbidity, and mortality. ${ }^{6,26}$

Central accumulation of body fat, estimated by the $\mathrm{WC}$ or $\mathrm{W} / \mathrm{H}$ ratio, is strongly associated with the above-mentioned metabolic abnormalities. ${ }^{28}$ In our study, central OB, irrespective of the criteria used, followed the BMI escalation and was more prominent in the obese participants of both sexes with females having a higher incidence rate. Using as cut-off points the WC of $102 \mathrm{~cm}$ in males and $88 \mathrm{~cm}$ in females, we found that $41.54 \%$ of our total population $339.1 \%$ of males and $43.8 \%$ of females) had abdominal obesity. These figures were comparable to those found in the ATTICA study ${ }^{13}$ (36.0\% and $43 \%$, respectively) but higher compared to the results of the nationwide study $^{13}$ (26.6\% and $35.8 \%$, respectively). Relatively high values of abdominal obesity were observed in southern Spain and Italy associated with high BMI, while lower values were found in northern Italy, France, UK, Denmark, and Sweden. ${ }^{25}$ The differences might be attributed to the variance that has been observed between different countries and even between regions of the same country. ${ }^{25}$ It is interesting to note that among subjects with normal BMI, a small proportion (2.3\% in males and 5.9\% in females) had central obesity. This is an additional alarming sign taking into account that European data on cardiovascular risk have shown that abdominal $\mathrm{OB}$ is a far better predictor of cardiovascular disease than BMI. ${ }^{29,30}$

The overall prevalence of OB in Thessaly is lower (26.6\%) but close to that found in a recent epidemiological survey in the USA (2003-2004) for nonHispanic whites aged $\geq 20$ years $(30.6 \%) .{ }^{5}$ In Europe, the frequency of $\mathrm{OB}$ is obviously heterogeneous and, according to a recent update from the International Obesity Task Force (IOTF), ${ }^{2}$ the prevalence of obesity in adults from European countries varies widely. The finding that in most European countries females are more obese than males was not detected in our study. For Greece, the IOTF's recent update showed an OB prevalence of $26.0 \%$ in males and $18.2 \%$ in females, which in fact reflects the results of the Kapantais et $\mathrm{al}^{12}$ study. Our estimation is comparable to the IOTF's report regarding the OB prevalence in males but not in females in which OB prevalence was higher. Due to the above-mentioned methodological limitations of the Kapantais et $\mathrm{al}^{12}$ study, we believe that $\mathrm{OB}$ prevalence in females is underestimated and that our results most likely represent values closer to the real prevalence of $\mathrm{OB}$ in adult Greek females. On the other hand differences between males and 
females have also been reported in adolescents from the area of Athens. ${ }^{31}$

Some potential limitations in our study should be noted. First, anthropometric measurements, although directly measured and not reported, were not obtained by the same person and this may be responsible for an inter-individual variability. Second, the region of Thessaly does not accurately represent the whole country as regards the urban/rural ratio as well as the socioeconomic characteristics with the result that extrapolation of our data to the whole country may not be appropriate.

In conclusion, overweight and obesity in the population of Thessaly are relatively high, especially in males, this being accompanied by the predictable increase in obesity related morbidity and mortality.

\section{REFERENCES}

1. Popkin BM, Doak CM, 1998 The obesity epidemic is a worldwide phenomenon. Nutr Rev 56: 106-114.

2. York DA, Rosnner S, Caterson I, et al, 2004 Prevention Conference VII: Obesity, a worldwide epidemic related to heart disease and stroke: Group I: Worldwide demographics of obesity. Circulation 110: e463-e470. (Updated data may be viewed at www.iotf.org).

3. The Global Challenge of Obesity and the International Obesity Task Force (www.iuns.org/features/obesity/obesity.htm).

4. Flegal KM, Carroll MD, Ogden CL, Johnson CL, 2002 Prevalence and trends in obesity among US adults, 1999-2000 JAMA 288:1723-1727.

5. Ogden CL, Carroll MD, Curtin LR, McDonwell MA, Tabak CJ, Flegal KM, 2006 Prevalence of overweight and obesity in the United States, 1999-2004. JAMA 295: 1549-1555.

6. The WHO Global Database on Body Mass Index. (www. who.int/nut/db bmi.htm, accessed December 2008).

7. WHO, 2003 Diet, Nutrition and the Prevention of Chronic Diseases. Report of a Joint WHO/FAO Expert Consultation. WHO Technical Report Series 916. Geneva: World Health Organisation.

8. National Institutes of Health, 1998 Clinical guidelines on the identification, evaluation and treatment of overweight and obesity in adults-the evidence report. Obes Res Suppl 2: 51S-209S.

9. Keys A, 1970 Coronary heart disease in seven countries. Circulation 41(suppl 1): 1-211.

10. Menotti A, Lanti M, Puddu PE, Kromhout D, 2000 Coronary heart disease incidence in northern European populations: a reanalysis of the seven countries study for the European coronary risk chart. Heart 84: 238-244.
11. Kafatos A, Diakatou A, Voukiklakis G, et al, 1997 Heart disease risk-factor status and dietary changes in the Cretan population over the past 30y: The Seven Countries Study. Am J Clin Nutr 65: 1882-1886.

12. Kapantais E, Tzotzas T, Ioannidis I, et al, 2006 First national epidemiological survey on the prevalence of obesity and abdominal fat distribution in Greek adults. Ann Nutr Metab 50:330-338.

13. Panagiotakos DB, Pitsavos C, Chrysohoou C, et al, 2004 Epidemiology of overweight and obesity in a Greek adult population: The ATTICA study. Obesity Res 12: 1914-1920.

14. Krassas GE, Kelestimur F, Micic D, et al, 2003 The Balkan Group for the Study of Obesity. Self-reported prevalence of obesity among 20,329 adults from large territories of Greece, Serbia and Turkey. Hormones (Athens) 2: 49-54.

15. Health, United States, 2001 Urban and Rural Health Chartbook. Rockville, Md: US Dept of Health and Human Services, Centers for Disease Control and Prevention. DHHS Publication PHS 2001-1232-1. (Available at http://www.cdc.gov/nchs/data/hus/hus01cht_ac.pdf, accessed December 2008).

16. Kuczmarski MF, Kuczmarski RJ, Najjar M, 2001 Effects of age on validity of self-reported height, weight, and body mass index: findings from the Third National Health and Nutrition Examination Survey, 1988-1994. J Am Diet Assoc 101: 28-34.

17. Population census 2001. General Secretariat of the National Statistical Service of Greece. http://statistics. gr/portal/page/portal/ESYE.

18. Black K 2004 Sampling and sampling distributions. In: Black K, (ed), Business Statistics for Contemporary Decision Making. 6th Edition, J. Wiley \& Sons, Inc, NJ; pp, 217-246.

19. Dobbelsteyn C, Joffres M, MacLean D, Flowerdew G, and the Canadian Heart Health Surveys Research Group, 2001 A comparative evaluation of waist circumference, waist-to-hip ratio and body mass index as indicators of cardiovascular risk factors: The Canadian Heart Surveys. Int J Obes Relat Metab Disord 25: 652-661.

20. James WPT, 2005 Assessing obesity: are ethnic differences in body mass index and waist classification criteria justified? Obes Rev 6: 179-181.

21. Garrow JS, Webster J, 1985 Quetelet's index (W/H2) as a measure of fatness. Int J Obes 9: 147-153.

22. WHO Obesity: Preventing and Managing the Global Epidemic. Report of a WHO Consultation on Obesity. World Health Organization: Geneva, 2000.

23. Flood V, Webb K, Lazarus R, Pang G, 1999 Use of selfreport to monitor overweight and obesity in populations: some issues for consideration. Aust N Z Public Health 24: 96-99.

24. Banks J, Marmot M, Oldfield Z, Smith JP, 2006 Disease and disadvantage in the United States and in England. JAMA 295: 2037-2045. 
25. Haftenberger M, Lahmann PH, Panico S, et al, 2002 Overweight, obesity and fat distribution in 50- to 64year-old participants in the European Prospective Investigation into Cancer and nutrition (EPIC). Public Health Nutr 5: 1147-1162.

26. Kannel WB, Wilson PW, Nam BH, D' Agostino RB, 2002 Risk stratification of obesity as a coronary risk factor. Am J Cardiol 90: 697-701.

27. Ogden CL, Carroll MD, Curtin LR, McDonwell MA, Tabak CJ, Flegal KM, 2006 Prevalence of overweight and obesity in the United States, 1999-2004. JAMA 295: 1549-1555.

28. Kaplan NM, 1989 The deadly quartet. Upper body obesity, glucose intolerance, hypertriglyceridemia, and hypertension. Arc Intern Med 149: 1514-1520.

29. Larsson B, 1988 Regional obesity as a health hazard in menprospective studies. Acta Med Scand Suppl 723: 45-51.

30. Panagiotakos DB, Pitsavos Ch, Skoumas Y, et al, 2008 Abdominal obesity, blood glucose and apolipoprotein $\mathrm{B}$ levels are the best predictors of the incidence of hypercholesterolemia (2001-2006) among healthy adults: the ATTICA study. Lipids Health Dis 7:11.

31. Chiotis D, Krikos X, Tsiftis G, Hatzisymeaon M, Maniati-Christidi M, Dacou-Voutetaki A, 2004 Body mass index and prevalence of obesity in subjects of Hellenic origin aged 0-18 years, living in the Athens area. Ann Clin Pediatr Unive Atheniensis 51:139-154. 